\title{
Bipolar disorder in pregnancy and childbirth: a systematic review of outcomes
}

\author{
Marie Rusner ${ }^{1,2^{*}}$ (D), Marie Berg ${ }^{2,3}$ and Cecily Begley ${ }^{2,4}$
}

\begin{abstract}
Background: Bipolar Disorder (BD) is a mental disorder usually diagnosed between 18 and 30 years of age; this coincides with the period when many women experience pregnancy and childbirth. As specific problems have been reported in pregnancy and childbirth when the mother has BD, a systematic review was carried out to summarise the outcomes of pregnancy and childbirth, in mother and child, when the mother has BD diagnosed before pregnancy.

Methods: An a priori protocol was designed and a systematic search conducted in PubMed, CINAHL, Scopus, PsycINFO and Cochrane databases in March 2015. Studies of all designs were included if they involved women with a diagnosis of bipolar disorder prior to pregnancy, who were pregnant and/or followed up to one year postpartum. All stages of inclusion, quality assessment and data extraction were done by two people. All maternal or infant outcomes were examined, and narrative synthesis was used for most outcomes. Meta-analysis was used to achieve a combined prevalence for some outcomes and, where possible, case and control groups were combined and compared.

Results: The search identified 2809 papers. After screening and quality assessement (using the EPHPP and AMSTAR tools), nine papers were included. Adverse pregnancy outcomes such as gestational hypertension and antepartum haemorrhage occur more frequently in women with BD. They also have increased rates of induction of labour and caesarean section, and have an increased risk of mood disorders in the postnatal period. Women with BD are more likely to have babies that are severely small for gestational age ( $<2$ nd-3rd percentile), and it appears that those women not being treated with mood stabilisers in pregnancy might not have an increased risk of having a baby with congenital abnormalities.
\end{abstract}

Discussion: Due to heterogeneity of data, particularly the use of differing definitions of bipolar disorder, narrative synthesis was used for most outcomes, rather than a meta-analysis.

Conclusions: It is evident that adverse outcomes are more common in women with BD and their babies. Large cohort studies examining fetal abnormality outcomes for women with BD who are not on mood stabilisers in pregnancy are required, as are studies on maternal-infant interaction.

Keywords: Bipolar disorder, Affective disorders, Mania, Pregnancy, Postpartum, Delivery, Parturition, Childbirth

\section{Background}

Bipolar Disorder (BD) is a severe affective mood disorder characterized by a wide range of lifelong mood changes varying between depressive, hypomanic, manic or mixed episodes $[1,2]$. The lifetime prevalence for the most common variations within the BD spectrum, BD-I

\footnotetext{
*Correspondence: marie.rusner@vgregion.se

'Department of Research, Södra Älvsborgs Hospital, Brämhultsvägen 53, SE-501 82 Borås, Sweden

${ }^{2}$ Institute of Health and Care Sciences, Sahlgrenska Academy, University of Gothenburg, Gothenburg, Sweden

Full list of author information is available at the end of the article
}

and BD-II, is reported as 1-2.4 \% [3, 4]. A recent study from Sweden reports that incidence and prevalence of $\mathrm{BD}$ has increased during the last 20 years [5]. BD entails a significant burden for those that are affected as well as high societal costs related to health care, sick leave and early retirement [6]. The Swedish study has found that in persons with $\mathrm{BD}$, despite similar education levels, employment levels are lower and disposable income is less compared to the general population. Also, persons with $\mathrm{BD}$ have more sick leave compared to the general population [5]. BD is a severe condition, and an example of 
this is that the suicide risk in people with this disorder is about 20-30 times greater than that for the general population [7].

The time when many women experience pregnancy, childbirth and early postpartum overlaps the period between 18 and 30 years when most women are diagnosed with $\mathrm{BD}$ [8]. Being pregnant and giving birth to a child is a key life transition event comprising engagement, growth and transformation [9]. Women with mental illness, however, often experience problems and increased risk of complications related to childbearing [10]. Female patients with psychiatric disorders seem to have more negative attributes with regard to sexuality and reproduction [11]. The complex picture of problems that women with BD face include: sexually risky behaviour during episodes of mania, health related risks for the mother and/or the baby, decisions regarding medication during pregnancy, as well as decisions related to unplanned/undesired pregnancy, and sexually transmitted infections [12-16].

As a basis for developing high quality healthcare with best health outcomes for mother and child when the pregnant woman has BD, there is need for a scientific overview of the risks. The aim of this paper is, through a systematic literature review, to summarise outcomes of pregnancy and childbirth, in mother and child, when the mother has bipolar disorder diagnosed before pregnancy.

\section{Methods}

The research question guiding this systematic review was: What are the outcomes of pregnancy and childbirth (childbirth defined as labour and birth, and the first year postpartum) for women with bipolar disorder and their fetus/infant, when compared with outcomes for women with bipolar disorder, who are not pregnant, experiencing labour and birth, or postnatal. We were open to all scientific findings in the field.

\section{Search strategy}

The use of the accepted definition of bipolar disorder $[1,2]$ was planned. An a priori protocol was designed, outlining the aim and procedure for the review and is available in the Additional file 1. An inclusion/exclusion criteria list was developed from identifying relevant PICOS (Table 1), and then tested with the PRESS criteria [17], to guide inclusion of all relevant studies. A comprehensive and systematic search was done in the following databases: PubMed, CINAHL, Scopus, PsycINFO and Cochrane, from inception until 10th of March 2015, to identify studies or existing systematic reviews. The final search string for PubMed is available in the Additional file 1, Table 2. A repeat search in PubMed and Cochrane
Library was conducted in March 2016 to check for any new papers that should be included in the discussion section, for comparison.

We limited our search to peer-reviewed papers. We planned to include randomised trials if the control groups could provide outcomes due to $\mathrm{BD}$, but none were found.

A total of 2809 papers were found in the five databases (PubMed $n=877$, CINAHL $n=240$, PsychINFO $n=512$, Scopus $n=1156$ and Cochrane $n=24)$. After deletion of duplicates by two reviewers (MR, MB), 1700 papers remained. Exclusion of papers by title and abstract was made by two reviewers (MR, MB) based on assessment of the inclusion and exclusion criteria. In case of disagreement the third reviewer (CB) was involved. This process ended in exclusion of 1652 papers. The full text of the remaining papers $(n=48)$ was read by three teams of two researchers each $(\mathrm{MR} / \mathrm{MB}, \mathrm{MR} / \mathrm{CB}, \mathrm{MB} / \mathrm{CB})$. Five further studies were added from their reference lists. Of these 53, 35 papers were excluded (Fig. 1). Reasons for exclusion were: drug related issues (21 papers, [14, 18-37]), no focus on the chosen study group (six papers, [38-43]), outcomes in women not diagnosed before pregnancy (two papers, [44, 45]), mixed groups bipolar disorder and schizophrenia (two papers, $[46,47]$ ), discussion paper (two papers, [48, 49]), gender mixed groups also including men (one paper, [50]), duplicates (one paper, [15]). Occasionally it was difficult to separate the different diagnoses that were included in the sample; for example, in Doyle et al. [46] it was not possible to find separate data for the three included groups: BD I, BD II and schizoaffective disorders bipolar type. In Mac Cabe et al. [47] it was difficult to determine whether women with additional diagnoses were included in the sample or not, so both these papers were excluded. Eighteen papers (15 studies and 3 reviews) were thus quality assessed by the three pairs.

A repeat search in PubMed and Cochrane Library was conducted in March 2016, using the same methodology, to check for any new papers that should be included in the discussion section, for comparison. Fifty-eight papers were found in PubMed in this second search and no papers in the Cochrane Library. Four new papers [51-54] were found to be topical for this review. Logsdon et al. 2015 [51] described maternal-infant interaction at 12 months postpartum in women with BD compared to women with unipolar depression and a control group without a major mood disorder. Marengo et al. 2015 [52] looked at how women with $\mathrm{BD}$ made reproductive decisions. Both of these papers are included in the discussion section only, for noting, as they were published too late to be included in the review. Taylor et al. 2015 [53] was excluded, as their description of the characteristics of pregnant women and their use of psychotropic medication was not relevant for this review. The fourth 
Table 1 PICOS and Key words

\begin{tabular}{ll}
\hline PICOS & Key words \\
\hline $\begin{array}{l}\text { Population: Women with established diagnosis of bipolar disorder prior } \\
\text { to pregnancy }\end{array}$ & $\begin{array}{l}\text { Bipolar disorder OR affective disorders, psychotic OR affective } \\
\text { psychosis OR mania }\end{array}$ \\
$\begin{array}{l}\text { Intervention/Exposure: Pregnancy, labour and birth, and the first year } \\
\text { post-partum }\end{array}$ & $\begin{array}{l}\text { Pregnancy OR postpartum period OR delivery, obstetric OR } \\
\text { parturition OR abortion, spontaneous OR abortion, induced } \\
\text { OR childbirth }\end{array}$ \\
$\begin{array}{l}\text { Comparison: Women with bipolar disorder, not experiencing pregnancy } \\
\text { or childbirth }\end{array}$ & $\begin{array}{l}\text { Women with bipolar disorder, not experiencing childbirth } \\
\begin{array}{l}\text { Outcome: All maternal or infant health outcomes. Papers that compared } \\
\text { effects of using different pharmaceutical treatments were excluded. }\end{array}\end{array}$ \\
$\begin{array}{l}\text { Study design: Qualitative studies, Meta-syntheses, Surveys, Cross-sectional } \\
\text { studies, Case reports, Experimental studies (RCTs), Quasi-experimental studies, } \\
\text { Observational studies, Systematic reviews, Meta-analyses }\end{array}$ & $\begin{array}{l}\text { The terms 'woman, fetus, neonate and infant' } \\
\text { Experimental, Randomised controlled trials, Quasi-experimental, } \\
\text { Observational, Systematic reviews, Meta-analyses }\end{array}$ \\
\hline
\end{tabular}

paper, a review and meta-analysis by Wesseloo et al. 2016 [54] was also not relevant for inclusion as it included women who had a psychotic or manic episode following childbirth, even if they had never had a diagnosis of $\mathrm{BD}$ in pregnancy.

\section{Quality assessment}

To assess the studies for quality the validated Effective Public Health Practice Project (EPHPP) tool [55] was used for original studies $(n=15)$, based on six categories including study design, selection bias and data collection methods. Each item was given a rating of strong, moderate or weak, based on how well the criteria were met. An overall strong, moderate or weak rating was awarded for studies with no, one, or two or more "weak" categories. We excluded six studies rated as "weak" [56-61]. The quality of the reviews $(n=3)$ was assessed using the AMSTAR tool $[62,63]$. Each of the eleven issues is rated with Yes, No, Can't answer or Not Applicable. Every yes is given one mark; 8 to 11 marks is "high quality", 4 to 7

Table 2 Final search string for PubMed

Bipolar disorder AND (pregnancy OR postpartum period OR delivery, obstetric OR parturition OR abortion, spontaneous OR abortion, induced)

("bipolar disorder"[MeSH Terms] OR ("bipolar"[All Fields] AND "disorder"[All Fields]) OR "bipolar disorder"[All Fields]) AND (("pregnancy"[MeSH Terms] OR "pregnancy"[All Fields]) OR ("postpartum period"[MeSH Terms] OR ("postpartum"[All Fields] AND "period" [All Fields]) OR "postpartum period"[All Fields]) OR ("delivery, obstetric" [MeSH Terms] OR ("delivery"[All Fields] AND "obstetric"[All Fields]) OR "obstetric delivery"[All Fields] OR ("delivery"[All Fields] AND"obstetric" [All Fields]) OR "delivery, obstetric"[All Fields]) OR ("parturition"[MeSH Terms] OR "parturition"[All Fields] OR "delivery, obstetric"[MeSH Terms] OR ("delivery"[All Fields] AND "obstetric"[All Fields]) OR "obstetric delivery"[All Fields]) OR ("abortion, spontaneous"[MeSH Terms] OR ("abortion"[All Fields] AND "spontaneous"[All Fields]) OR "spontaneous abortion"[All Fields] OR ("abortion"[All Fields] AND "spontaneous" [All Fields]) OR "abortion, spontaneous"[All Fields]) OR ("abortion, induced"[MeSH Terms] OR ("abortion"[All Fields] AND "induced" [All Fields]) OR "induced abortion"[All Fields] OR ("abortion"[All Fields] AND "induced"[All Fields]) OR "abortion, induced"[All Fields])) is "medium", and 0 to 3 is "low quality". We excluded all three reviews due to "low quality" [64-66].

The 9 remaining papers were included, 4 of which had a "strong" rating, and 5 a "moderate" (Table 3).

\section{Data extraction and analysis}

Three teams of two reviewers extracted key findings from each study, as well as potential explanations given by the authors for results, and their recommendations, using a pre-designed data collection form. Any disagreements were resolved by consensus. Meta-analysis was not always possible because of heterogeneity in the majority of studies (due to differing definitions of BD, or non-similar cohorts), so a descriptive narrative synthesis was used for most outcomes. When appropriate (similar definitions of BD), simple meta-analysis was used to achieve a combined prevalence. In a few cases, we were able to combine and compare case and control groups, when similar methods had also been used in two or more studies. Odds ratios were computed using MedCalc online statistical software (https://www.med calc.org/download.php) and heterogeneity between studies was calculated using RevMan, the Cochrane Collaboration software (Review Manager, 2014). The study by Jablensky et al. [67] had a mixed cohort that included only $55 \%$ of women with pre-existing $\mathrm{BD}$, so has been left out of all meta-analyses performed.

\section{Results}

In the following pages we describe the identified outcomes of pregnancy and childbirth in mothers, and their children, when the mother has $\mathrm{BD}$ diagnosed before pregnancy.

\section{Description of included studies}

Characteristics of the nine included studies are presented in Table 3. Outcome data measured were risks or complications for the pregnancy, mother, fetus and/or baby. Seven of the nine papers had a retrospective 


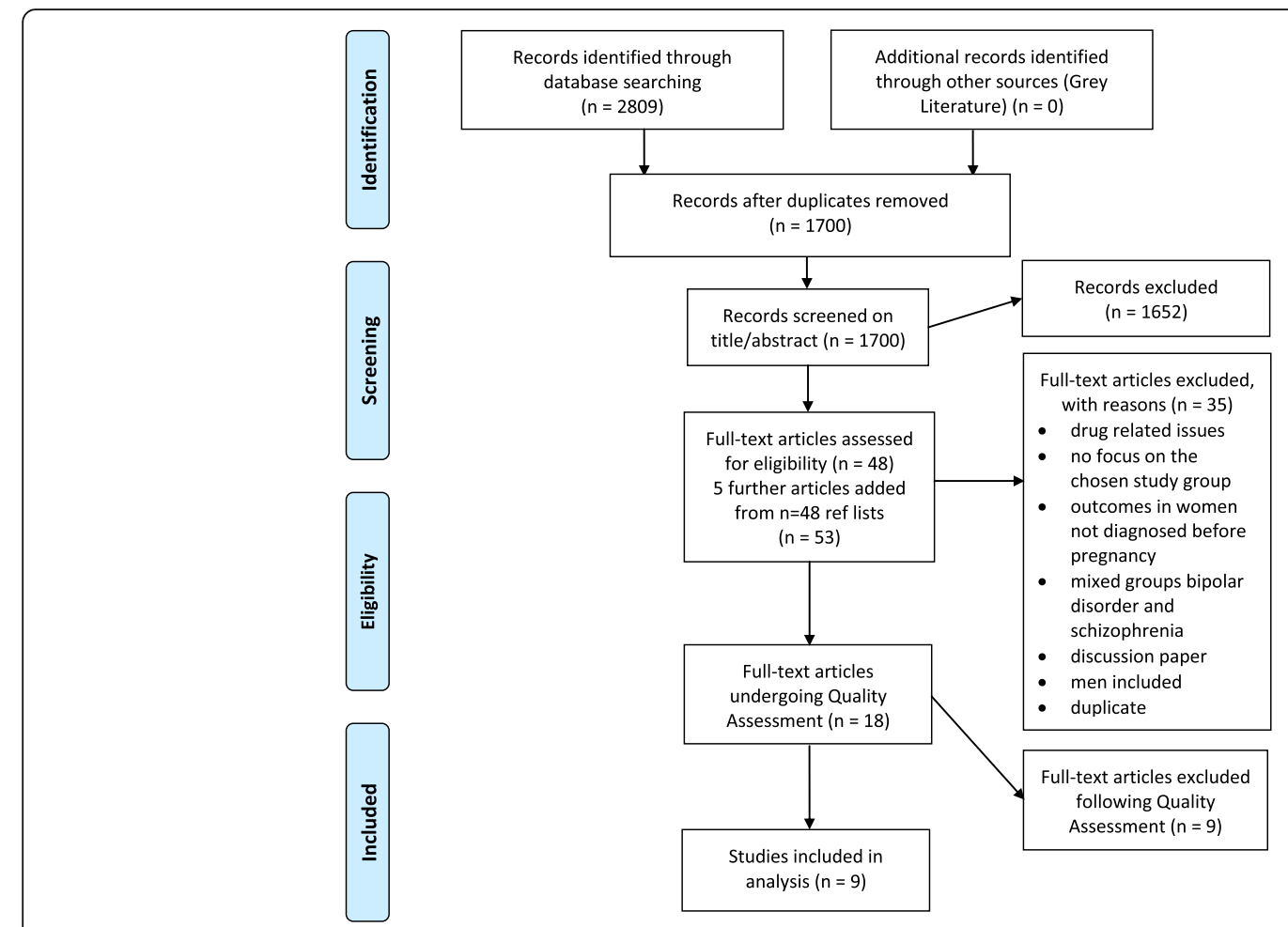

Fig. 1 Study selection flow diagram

design. Of these, three comprised data on outcomes in pregnancy and birth, one had postpartum data only (from 27 days to one year), and five comprised data on all these three episodes (Table 3). There were no restrictions for age, parity, ethnicity or other variables. We included papers written in the languages English, German, French and Swedish, and had no restrictions for age, parity, ethnicity or other variables.

The studies were published from year 2000 to 2015; one each performed in Turkey [68], Sweden [69], Australia [67], Taiwan [70], Canada [71] and Denmark [72]; two in United Kingdom [73, 74], and one study using data from an international data base of Lithium treated persons including Austria, Canada, the Czech Republic, Denmark, Germany and Sweden [75]. Four of the publications were cohort studies, and five case control studies where outcomes of pregnancy were compared for women with BD and those without. The objectives of the papers varied.

Definitions of bipolar disorder used in the papers varied from BD (DSM-IV not specified), BD-I and BD-II (DSM-IV), BD (ICD-10 codes F30-31, F34.0 and F38), RDC [76], BD (ICD-9 codes 296.0 and 296.2-5), BD (ICD-8 codes 296.19, 296.39 and 298.19), BD (ICD-9, ICD-10CA not specified) and BD (ICD-9-CM codes 295.XX, 296.0X, 296.1X, 296.4X, 296.5X, 296.6X, 296.7X, 296.80 or 296.89). (Table 3) Authors' definitions have been used in this review.

\section{Mood episodes (Table 4)}

Mood episodes during pregnancy and post-partum in the women with $B D$

Three studies reported results both on mood episodes during pregnancy or the post-partum period. Akdeniz et al. [68] showed that $32 \%$ of the women with BD had at least one mood episode during pregnancy or within the first month after childbirth. Di Florio et al. [73] reported that $49.8 \%$ of the women with BD-I and $42.2 \%$ of women with BD-II had a mood episode in pregnancy or the post-partum period. Women who had a mood episode during their 1st pregnancy were, according to Akdeniz et al. [68], more likely to have another episode postpartum (OR 9.6 (95 \% CI, 1.00-91.96). Also, women who had a mood episode in the 1st post-partum period were more likely to have a mood episode in the 2nd post-partum period (OR 3.6, $95 \% \mathrm{CI}, 0.25-50.33$ ). Di Florio et al. [73] reported that women with BD-II had a higher incidence of any perinatal mood episode compared with women with BD-I (BD-II $18.4 \%$ and BD-I $8.6 \%$, (chi-square $=10.38$, d.f. $=1, p<0.002$ (calculated by review authors)) and that the mood episodes were significantly more common during the first month postpartum than during pregnancy (BD-I OR $44.595 \% \mathrm{CI}$ 26.90-76.00 and BD II OR $4.795 \%$ CI 2.40-9.80). Grof et al. [75] show that episodes occurred significantly more often in the post-partum period than before and during pregnancy. 
Table 3 Characteristics of 9 included studies

\begin{tabular}{|c|c|c|c|c|c|c|c|c|}
\hline $\begin{array}{l}\text { First author, year of } \\
\text { publication }\end{array}$ & $\begin{array}{l}\text { EPHPP } \\
\text { rating }\end{array}$ & Aim of study & Study design & Diagnostic tool & Sample & Pharmaceutic treatment & $\begin{array}{l}\text { Length of } \\
\text { follow-up }\end{array}$ & Country \\
\hline Akdeniz 2003 [68] & M & $\begin{array}{l}\text { To evaluate and emphasise } \\
\text { the impact of clinical and } \\
\text { psychosocial risk factors } \\
\text { associated with pregnancy } \\
\text { and/or the postpartum } \\
\text { period during the course } \\
\text { of BD in women who had } \\
\text { given birth }\end{array}$ & $\begin{array}{l}\text { Retro-spective } \\
\text { cohort study }\end{array}$ & $\begin{array}{l}\text { BD (DSM-IV). } \\
\text { Different types } \\
\text { are not reported. }\end{array}$ & $\begin{array}{l}72 \text { women with BD ( } 252 \\
\text { pregnancies and } 160 \\
\text { childbirths) Analysed a } \\
\text { sub group: ( } n=23) \text { : every } \\
\text { mood episode that began } \\
\text { during pregnancy and in } \\
\text { postpartum period } \\
\text { following birth at gestation } \\
26 \text { weeks+ }\end{array}$ & $\begin{array}{l}\text { Of women with post- } \\
\text { partum episodes }(n=26) \\
21 \text { had received } \\
\text { psychotropic medication. } \\
\text { None of the women } \\
\text { with post-partum } \\
\text { episodes took Lithium } \\
\text { during pregnancy. }\end{array}$ & $\begin{array}{l}\text { Pregnancy, } \\
\text { birth and up } \\
\text { to one month } \\
\text { post-partum }\end{array}$ & Turkey \\
\hline Bodén 2012 [69] & S & $\begin{array}{l}\text { To investigate the risks of } \\
\text { adverse pregnancy and birth } \\
\text { outcomes for treated and } \\
\text { untreated bipolar disorder } \\
\text { during pregnancy. }\end{array}$ & $\begin{array}{l}\text { Retro-spective } \\
\text { case control } \\
\text { study }\end{array}$ & $\begin{array}{l}\text { BD (ICD-10 codes } \\
\text { F30-31) }\end{array}$ & $\begin{array}{l}\text { A cohort of } 332,137 \text { women } \\
2005-2009 \text {. Women with a } \\
\text { record of at least two BD } \\
\text { diagnoses }(n=874), 320 \\
\text { treated with mood stabiliser, } \\
554 \text { untreated, compared } \\
\text { with all other women } \\
\text { giving birth }(n=331,263)\end{array}$ & $\begin{array}{l}\text { Treated BD with mood } \\
\text { stabiliser (Lithium, a } \\
\text { ntipsycotics or } \\
\text { anticonvulsants) }\end{array}$ & $\begin{array}{l}\text { Pregnancy } \\
\text { and birth }\end{array}$ & Sweden \\
\hline Di Florio 2013 [73] & M & $\begin{array}{l}\text { To investigate the occurrence } \\
\text { and timing of perinatal mood } \\
\text { episodes in women with BD-I } \\
\text { and BD-II }\end{array}$ & $\begin{array}{l}\text { Retro-spective } \\
\text { cohort study }\end{array}$ & $\begin{array}{l}\text { BD-I and BD-II } \\
\text { (DSM- IV) }\end{array}$ & $\begin{array}{l}1212 \text { women ( } 980 \text { with } \\
\text { BD-I (1404 births), } 232 \text { with } \\
\text { BD-II (424 births) }\end{array}$ & $\begin{array}{l}\text { Pharmacotherapy not } \\
\text { reported. }\end{array}$ & $\begin{array}{l}\text { Pregnancy, } \\
\text { birth and up } \\
\text { to one year } \\
\text { postpartum }\end{array}$ & United Kingdom \\
\hline Di Florio 2014 [74] & M & $\begin{array}{l}\text { To test the hypothesis that } \\
\text { risk of perinatal mood episodes } \\
\text { is greater after first pregnancy }\end{array}$ & $\begin{array}{l}\text { Retro-spective } \\
\text { cohort study }\end{array}$ & $\begin{array}{l}\text { BD-I and BD-II } \\
\text { (DSM-IV) }\end{array}$ & $\begin{array}{l}1212 \text { women ( } 934 \text { with } \\
\text { BD-I (1404 births), } 278 \text { with } \\
\text { BD-II (424 births) }\end{array}$ & $\begin{array}{l}\text { No details on drug } \\
\text { management reported. }\end{array}$ & $\begin{array}{l}\text { Pregnancy, } \\
\text { birth and up } \\
\text { to one year } \\
\text { postpartum }\end{array}$ & United Kingdom \\
\hline Grof 2000 [75] & M & $\begin{array}{l}\text { To examine statistically the } \\
\text { clinical course of } 28 \text { women } \\
\text { with typical bipolar disorder, } \\
\text { type I, who became pregnant } \\
\text { prior to receiving successful } \\
\text { lithium prophylaxis }\end{array}$ & $\begin{array}{l}\text { Retro-spective } \\
\text { case/control } \\
\text { study }\end{array}$ & $\begin{array}{l}\text { BD (Re-search } \\
\text { Diagnostic Criteria, } \\
\text { (Spitzer et al. 1978)) }\end{array}$ & $\begin{array}{l}28 \text { women with } \mathrm{BD} \text { ( } 56 \\
\text { pregnancies) and no } \\
\text { Lithium prophylaxis; } 33 \\
\text { childless women with BD } \\
\text { (controls) }\end{array}$ & $\begin{array}{l}\text { None had prophy-lactic } \\
\text { Lithium during pregnancy, } \\
\text { but } 4 \text { took Lithium for } \\
\text { depression towards end } \\
\text { of pregnancy. Women } \\
\text { with acute episodes } \\
\text { received Lithium as } \\
\text { treatment. }\end{array}$ & $\begin{array}{l}\text { Pregnancy, } \\
\text { birth and up } \\
\text { to } 9 \text { months } \\
\text { postpartum }\end{array}$ & $\begin{array}{l}\text { A world-wide } \\
\text { ethnic popul- } \\
\text { ation (the majority } \\
\text { from Canada). }\end{array}$ \\
\hline Jablensky 2005 [67] & M & $\begin{array}{l}\text { To determine the frequency, } \\
\text { nature, and severity of } 25 \\
\text { obstetric complic-ations in } \\
\text { women with affective disorders } \\
\text { and those with no psychiatric } \\
\text { disorder }\end{array}$ & $\begin{array}{l}\text { Case control } \\
\text { study }\end{array}$ & $\begin{array}{l}\text { BD (ICD-9 codes } \\
296.0 \text { and 296.2-5) }\end{array}$ & $\begin{array}{l}763 \text { women with } \mathrm{BD}, 1,301 \\
\text { pregnancies; } 1,831 \text { women } \\
\text { (3,129 pregnancies) with } \\
\text { no history of mental health } \\
\text { difficulties (controls) }\end{array}$ & $\begin{array}{l}\text { No specific information } \\
\text { on prescription of } \\
\text { medication available. }\end{array}$ & $\begin{array}{l}\text { Pregnancy } \\
\text { and birth }\end{array}$ & Australia \\
\hline Lee 2010 [70] & S & $\begin{array}{l}\text { To investigate pregnancy } \\
\text { outcomes among women with } \\
\text { bipolar disorder, compared } \\
\text { with women with no history } \\
\text { of mental illness, using } \\
\text { nationwide population-based }\end{array}$ & $\begin{array}{l}\text { Retro-spective } \\
\text { case control } \\
\text { study }\end{array}$ & $\begin{array}{l}\text { BD (ICD-9-CM } \\
\text { codes 295.XX, } \\
296.0 X, 296.1 X \\
296.4 X, 296.5 X \\
296.6 X, 296.7 X \\
296.80 \text { or } 296.89)\end{array}$ & $\begin{array}{l}337 \text { women with BD; } \\
528,061 \text { women with no } \\
\text { history of mental health } \\
\text { difficulties (controls) }\end{array}$ & $\begin{array}{l}\text { Information on medical } \\
\text { treatment not reported. }\end{array}$ & $\begin{array}{l}\text { Pregnancy } \\
\text { and birth }\end{array}$ & Taiwan \\
\hline
\end{tabular}


Table 3 Characteristics of 9 included studies (Continued)

\begin{tabular}{|c|c|c|c|c|c|c|c|c|}
\hline Mei-Dan 2015 [71] & $S$ & $\begin{array}{l}\text { To evaluate the risk of adverse } \\
\text { perinatal outcomes among } \\
\text { pregnant women previously } \\
\text { hospitalised for BD }\end{array}$ & $\begin{array}{l}\text { Population } \\
\text { based case } \\
\text { control study }\end{array}$ & $\begin{array}{l}\text { BD (ICD-9, ICD-10CA, } \\
\text { DSM-IV) }\end{array}$ & $\begin{array}{l}1859 \text { women with BD; } \\
3724 \text { women with major } \\
\text { depressive disorder (controls); } \\
\text { 432,358 women with no } \\
\text { mental illness (controls) }\end{array}$ & $\begin{array}{l}\text { No information } \\
\text { regarding medical } \\
\text { treatment. }\end{array}$ & $\begin{array}{l}\text { Pregnancy, } \\
\text { birth and up } \\
\text { to } 27 \text { days } \\
\text { postpartum }\end{array}$ & Canada (Ontario) \\
\hline Munk-Olsen 2009 [72] & $\mathrm{S}$ & $\begin{array}{l}\text { To compare mothers and } \\
\text { nonmothers to assess whether } \\
\text { childbirth increases the risk for } \\
\text { psych-iatric readmission and } \\
\text { to identify pre-dictors of } \\
\text { psychiatric readmission during } \\
\text { the first } 12 \text { months postpartum. }\end{array}$ & $\begin{array}{l}\text { Population } \\
\text { cohort register } \\
\text { study, prospec- } \\
\text { tively studied }\end{array}$ & $\begin{array}{l}\text { BD (ICD-8 codes } \\
\text { 296.19, 296.39 and } \\
\text { 298.19. ICD-10 } \\
\text { codes F30,F31, } \\
\text { F34.0 and F38) }\end{array}$ & $\begin{array}{l}\text { All women born in Denmark } \\
\text { between Jan 1, } 1955 \text { and } \\
\text { July 1, } 1990 \text { who were } \\
\text { alive on their } 15 \text { th birthday } \\
\text { and who had at least } 1 \\
\text { psychiatric admission during } \\
\text { the study period: January } \\
\text { 1, 1973, through June } \\
30,2005 \text {. Analysis group } \\
2 \text { contained } 56 \text { women } \\
\text { with bipolar disorder }\end{array}$ & $\begin{array}{l}\text { No data on } \\
\text { pharmacological } \\
\text { treatment available. }\end{array}$ & $\begin{array}{l}\text { Postpartum up } \\
\text { to } 12 \text { months }\end{array}$ & Denmark \\
\hline
\end{tabular}

$\overline{B D}$ Bipolar Disorder, S Strong, $M$ Moderate 
Table 4 Mood episodes in pregnancy and early postpartum period for women with bipolar disorder

First author, year of publication

Mood episodes

Akdeniz 2003 [68]

Di Florio 2013 [73] Perinatal episodes across the mood disorder spectrum

Di Florio 2014 [74] Mood disorders and parity
Key findings: reported by authors

In $13.9 \%(n=10)$, the BD illness started in the peripartum period.

Twenty-three (32\%) women with BD reported at least one mood episode during pregnancy or within the first month after childbirth.

Eleven mood episodes occurred in pregnancy

(11 out of 252 pregnancies (4.4\%)) and which

started between 2nd and 8th pregnancy months.

Mean duration of episode was 5.5 weeks (SD 3.8, range 1-12)

Twenty-six mood episodes occurred in the first month postnatal (26 out of 160 births (16.3\%)). Mean duration of episode was 4.5 weeks (SD 4.9, range 1-23.5).

Women who had a mood episode during their

1st pregnancy, were more likely to have another episode postpartum (OR $9.6(95 \% \mathrm{Cl}, 1.002-$ 91.964)).

Women were more likely to have

a postpartum mood episode after the birth of the irst child. Women who had a mood episode in the 1st post-partum period were more likely to have a mood episode in the 2nd post-partum period (OR 3.6 (95\% Cl, 0.257-50.330)).

Women with BD-1: $49.8 \%$ had a mood episode in pregnancy or the post-partum period (pregnancy $8.6 \%$, postpartum period within 12 months of

childbirth $91.4 \%$ ). More than $20 \%$ were affected by mania or psychotic depression in the pregnancy or the post-partum period. $25 \%$ had an episode of non-psychotic depression.

Women with BD-II: $42.2 \%$ had a mood

episode in pregnancy or the post-partum period (pregnancy $18.4 \%$, postpartum period within 12 months of childbirth $81.6 \%$ ). Women with BD-II had a higher incidence of any perinatal mood episode compared with women with BD-I (chi-square $=10.38$ d.f. $=1, p<0.002$ (calculated by review authors). d.f. $=1, p<0.002$ (calculated by review authors).
The mood episodes were significantly more common The mood episodes were significantly more commo during the first month post-partum than during
pregnancy (BD-I OR 44.5 $95 \% \mathrm{Cl} 26.9-76.0$ and BD II OR $4.795 \%$ Cl 2.4-9.8).

Women with BD-I: $35 \%$ reported an episode (mania/ psychotic depression) in the first pregnancy, $20.5 \%$ in second pregnancy and $14.6 \%$ in subsequent pregnancies. Rates of depression were similar across all pregnancies and postpartum periods.
Potential mechanisms suggested by authors

Key recommendations made by authors

Biological factors such as onset of BD at an early age, antenatal mood episode and obstetric complications appeared to influence the risk, but psychosocial factors did not.

Need rigorous prospective studies. Avoid discontinuing lithium treatment too abruptly.
Only most severe episodes were rated, so other less severe disturbances may not have been recorded; rates of $\mathrm{BD}$ recurrence in pregnancy may thus be artificially low.

Women having their first baby are more anxious and stressed, due to lack of experience Multiparous women with BD may be more aware of the possibility of postnatal episodes, and may start treatment prophylactically.
Clinical studies on the effect of parity on mood disorders should also investigate possible effect of medication reducing the risk of perinatal relapse. 
Table 4 Mood episodes in pregnancy and early postpartum period for women with bipolar disorder (Continued)

\begin{tabular}{|c|c|c|c|}
\hline & $\begin{array}{l}\text { Women with BD-II: Rates of depression: first pregnancy } \\
46 \% \text { and second pregnancy } 33 \% \text {. } \\
\text { A significant association between parity and mood } \\
\text { episodes within } 6 \text { weeks postpartum was found. } \\
\text { There was no significant association between parity } \\
\text { and mood episodes in pregnancy or later postpartum. }\end{array}$ & & \\
\hline Grof 2000 [75] & $\begin{array}{l}\text { Five out of } 28 \text { women had a relapse during pregnancy } \\
(18 \%) \text {, all in the last five weeks of pregnancy. Seven } \\
(25 \%) \text { had a postpartum relapse: } 1 \text { to } 5 \text { times, lasting } \\
3.5 \text { months in average, } 42 \% \text { of these were manic. } \\
\text { Postpartum episodes were significantly more than the } \\
\text { other two periods (before and during pregnancy). } \\
\text { Pregnancy seemed to confer a protective effect. In } \\
\text { pregnancy, the mean rate of recurrence was } 0.14 \text {, } \\
\text { whereas mean rate in the } 9 \text { months prior to pregnancy } \\
\text { was } 0.43(p<0.05 \text { ). Duration was also less (mean of } 0.9 \\
\text { weeks during pregnancy, compared with mean of } 6.1 \\
\text { weeks before pregnancy, } p<0.01) \text {. Duration postpartum } \\
\text { was mean } 12.2 \text { weeks compared } \\
\text { to mean } 0.9 \text { in pregnancy, } p<0.001 \text {. }\end{array}$ & $\begin{array}{l}\text { May be due to placental hormones increasing } \\
\text { throughout pregnancy, and abrupt cessation } \\
\text { after birth. }\end{array}$ & $\begin{array}{l}\text { Stop psychotropic medication in pregnancy, } \\
\text { but continue to monitor women. Maybe } \\
\text { recommence medication in the last } 6 \text { weeks } \\
\text { of pregnancy. }\end{array}$ \\
\hline Mei-Dan 2015 [71] & $\begin{array}{l}3.6 \%(n=66) \text { of BD were hospitalised for psychiatric } \\
\text { reasons during the index pregnancy. (this is more than } \\
\text { for the major depressive disorder group: } 1.9 \%(n=69)\end{array}$ & & Women with BD need more social support \\
\hline Munk-Olsen 2009 [72] & $\begin{array}{l}\text { Women with previous diagnoses of } \mathrm{BD} \text {, had the highest } \\
\text { risk of readmission } 10 \text { to } 19 \text { days postpartum (RR, } 37.22 \text {; } \\
95 \% \mathrm{Cl}, 13.58-102.04) \text { compared with mothers with BD } \\
\text { who gave birth } 6 \text { to } 11 \text { months earlier. Cumulative } \\
\text { incidence of admission } 0-3 \text { months postpartum was } \\
22 \% \text {. During the first postpartum year, } 26.9 \% \text { of all } \\
\text { women with BD predating childbirth were admitted. }\end{array}$ & $\begin{array}{l}\text { May be due to decrease of hormones post } \\
\text { birth. Pregnancy, a time of emotional well- } \\
\text { being, provides protection from BD. }\end{array}$ & $\begin{array}{l}\text { Women with } \mathrm{BD} \text { who are pregnant or } \\
\text { considering pregnancy need careful } \\
\text { monitoring and relevant psychoeducation. }\end{array}$ \\
\hline
\end{tabular}

BD Bipolar Disorder, CI Confidence Interval, OR Odds Ratio 


\section{Mood episodes during pregnancy}

Occurrence of mood episode during pregnancy was reported in four studies. In a study by Grof et al. [75] $18 \%$ (five out of 28 women) had a relapse during pregnancy, all in the last five weeks of pregnancy. Combining the results of Akdeniz et al. [68] and Di Florio et al. [73] (as both studies used the DSM-IV definition) gives an overall prevalence for a mood episode during pregnancy of $9.3 \%$ (104 women out of 1116).

Di Florio et al. [74] found that $35 \%$ of the women with BD-I reported an episode (mania/psychotic depression) in the first pregnancy, $20.5 \%$ in second pregnancy and $14.6 \%$ in subsequent pregnancies. For women with BD-II the rates of depression in first pregnancy were $46 \%$ and second pregnancy $33 \%$. Rates of depression were similar across all pregnancies and postpartum periods.

\section{Mood episodes post-partum}

Occurrence of mood episodes in the post-partum period was reported in four studies. In the study by Grof et al. [75], $25 \%$ (seven out of 28) of the women had a postpartum relapse from 1 to 5 times, lasting 3.5 months on average; $42 \%$ of these were manic. Combining the results of Akdeniz et al. [68] and Di Florio et al. [73] for mood episodes post-partum shows a prevalence of $79.2 \%$ (812 out of 1024 births).

There was no significant association between parity and mood episodes in pregnancy or later post-partum according to Di Florio [74]. However, a significant association between parity and mood episodes within 6 weeks postpartum was found, with primiparous women being more likely to experience an episode.

\section{Admission during pregnancy}

Mei-Dan et al. [71] reported that $3.6 \%(n=66)$ of the women with $\mathrm{BD}$ were hospitalised for psychiatric reasons during pregnancy. This is more than for women with major depressive disorder, where $1.9 \% \quad(n=69)$ were admitted during pregnancy. Risk calculations for admission during pregnancy were not reported.

\section{Readmission post-partum}

Munk-Olsen et al. [72] showed in a register-based cohort study (study period 1973-2005) that $26.9 \%$ of all Danish women with BD with previous psychiatric admission(s) before birth of their first child were readmitted during the first year post-partum. That is almost twice as high compared to women with schizophrenia-like disorders $(15.7 \%)$. The highest risk of readmission was 10 to 19 days postpartum (RR, 37.22; $95 \% \mathrm{CI}, 13.58-$ 102.04) compared with mothers with the same diagnoses who gave birth 6 to 11 months earlier. The cumulative incidence of admission 0 to 3 months postpartum was $22 \%$.
Pregnancy and childbirth related issues and complications (Table 5)

Non spontaneous (artificial) start of childbirth (induction or planned caesarean section)

One retrospective cohort study [69] found that women without BD had a rate of induction of labour of $20.7 \%$; in women with BD without treatment it was $30.9 \%$, Adjusted Odds Ratio (AOR) 1.57 (95 \% CI 1.30 to 1.90); in women with BD with treatment it was $37.5 \%$, AOR 2.12 (95\% CI 1.68 to 2.67). Women without BD had a rate of caesarean birth of $16.8 \%$; in women with $\mathrm{BD}$ without treatment it was $23.5 \%$, AOR 1.45 (95\% CI 1.18 to 1.78 ); in women with $\mathrm{BD}$ with treatment the rate of caesarean birth was $25.6 \%$, AOR 1.56 (95\% CI 1.20 to 2.03) [69].

\section{Gestational diabetes}

One Swedish register study examined the relationship between $\mathrm{BD}$ and gestational diabetes. The analysis did not find any increased risk for gestational diabetes in either pharmaceutical-treated (OR 1.18 (95 \% CI 0.552.56)) or untreated women with $\mathrm{BD}$, compared with those without (OR 1.06 (95 \% CI 0.56-2.02)) [69].

\section{Gestational hypertension}

One population-based national study in Taiwan found that women with $\mathrm{BD}$ were more likely to have gestational hypertension than pregnant women with no history of mental health difficulties. The odds ratio (AOR) was 2.81 when adjusted for maternal age, education level, marital status, infant gender, parity, family months income, parental age difference and parental education level (95 \% CI 2.53-3.10) [70].

\section{Antepartum hemorrhage}

One cohort study showed that women with BD in Australia were more likely to have antepartum haemorrhage than pregnant women with no history of mental health difficulties (unadjusted OR 1.66 (95 \% CI 1.152.39)). When adjusting for maternal age, parity, plurality, marital status, originality, and sex, the increased risk of obstetric complications remained (AOR 1.60, $95 \% \mathrm{CI}=$ 1.11-2.32). However, those who developed BD after the index birth were at no more risk during pregnancy and birth than the women without mental health difficulties (OR 1.02, 95 \% CI = 0.92-1.12) [67].

\section{Placenta praevia}

One cohort study showed that women with BD were more likely to have placenta praevia than pregnant women with no history of mental health difficulties (OR $2.0495 \%$ CI 1.11-3.73). After adjustment for maternal age, parity, plurality, marital status aboriginality and sex the risk remained (AOR 2.13; 95 \% CI 1.15-3.94) [67]. 
Table 5 Obstetric complications in women with bipolar disorder

\begin{tabular}{lll}
\hline $\begin{array}{l}\text { First author, year of Key findings: reported by authors } \\
\text { publication }\end{array}$ & $\begin{array}{l}\text { Potential mechanisms suggested } \\
\text { by authors }\end{array}$ & $\begin{array}{l}\text { Key recommendations made } \\
\text { by authors }\end{array}$ \\
\hline
\end{tabular}

Obstetric complic-ations

Jablensky 2005 [67] Women with pre-existing BD had a significantly increased risk of obstetric complications (OR 1.13, $95 \% \mathrm{Cl}=1.02-1.25)$, whereas those who developed $\mathrm{BD}$ after the index birth were at no more risk than the women without mental health difficulties (OR 1.02, $95 \% \mathrm{Cl}=0.92-1.12)$ (Chi-square $=157.56$, $\mathrm{df}=8, p<0.0001)$.

Antepartum hemorrhage

Jablensky 2005 [67] Women with BD were more likely to have antepartum haemorrhage than pregnant women with no history of mental health difficulties (adjusted OR 1.60 (95\% Cl 1.11-2.32)).

Placenta praevia

Jablensky 2005 [67] Women with BD were more likely to have placenta praevia than pregnant women with no history of mental health difficulties (adjusted OR $2.13(95 \% \mathrm{Cl}$ 1.15-3.94)).

Women with pre-existing BD had a significantly increased risk of obstetric complications (OR 1.13, $95 \% \mathrm{Cl}=1.02-1.25)$, whereas those who developed $\mathrm{BD}$ after the index birth were at no more risk than the women without mental health difficulties (OR 1.02, $95 \% \mathrm{Cl}=0.92-1.12)$ (Chi-square $=157.56$, $\mathrm{df}=8, p<0.0001)$

Gestational hypertension

Lee 2010 [70]

Women with $\mathrm{BD}$ were more likely to have gestational hypertension ( $1.5 \%$ vs. $0.5 \%)$ than pregnant women with no history of mental health difficulties $(p<0.02)$.

Gestational diabetes

Lee 2010 [70]

No difference in rates of gestational diabetes between women with and without $\mathrm{BD}$.

Bodén 2012 [69] No increased risk for gestational diabetes in either treated or untreated women with $\mathrm{BD}$ compared to women without $\mathrm{BD}$.

Induction/elective CS

Bodén 2012 [69] Instrumental birth: Women without BD $24.7 \%$; BD without treatment $33.0 \%$, AOR $1.49(95 \% \mathrm{Cl} 1.24$ to 1.81); BD with treatment $34.1 \%$, AOR $1.39(95 \% \mathrm{Cl}$ 1.09 to 1.79 )

Caesarean birth: Women without BD $16.8 \%$; BD without treatment $23.5 \%$, AOR 1.45 (95\% Cl 1.18 to 1.78); BD with treatment $25.6 \%$, AOR 1.56 (95\% Cl 1.20 to 2.03 )

Non-spontaneous start of labour: Women

without BD $20.7 \%$ : BD without treatment $30.9 \%$, AOR $1.57(95 \% \mathrm{Cl} 1.30$ to 1.90$)$; BD with treatment $37.5 \%$, AOR 2.12 (95\% Cl 1.68 to 2.67 )

Preterm birth

Bodén 2012 [69]

The risk of preterm birth (before 37 weeks gestation) was increased for women with $\mathrm{BD}$, both for the treated and the untreated, compared with women without $\mathrm{BD}$. Women without BD $4.8 \%$; BD without treatment $7.6 \%$, AOR 1.48 (95\% Cl 1.08 to 2.03); BD with treatment $8.1 \%$, AOR 1.50 (95\% Cl 1.01 to 2.24 ).

Lee 2010 [70] Women with BD were more likely to have preterm births (14.2\% vs $6.9 \%$ ) than pregnant women with no history of mental health difficulties (AOR 2.08 $(95 \% \mathrm{Cl} 1.53-2.83)$
Possibly due more to clustering of adverse maternal characteristics than to any one factor

Possibly due more to clustering of adverse maternal characteristics than to any one factor

Research required into environmental and genetic reproductive risks.
Research required into environmental and genetic reproductive risks
None

None

Mood stabilising treatment is not necessarily the sole reason for increased risk of adverse outcomes.
None
Smoking could be a large part of the causation 
Table 5 Obstetric complications in women with bipolar disorder (Continued)

\begin{tabular}{|c|c|c|c|}
\hline Mei-Dan 2015 [71] & $\begin{array}{l}\text { Preterm birth was defined as }<37 \text { gestational weeks. } \\
\text { Higher prevalence for BD women } 11.4 \%, 212 \text { out of } \\
\text { 1858) and the BD group together with the 'major } \\
\text { depressive disorder' group with preterm birth }(11.4 \% \text {, } \\
N=405) \text { did, together, show increased prevalence above } \\
\text { the referent group (6.2 \%, } n=27000) \text {. Crude OR for BD: } \\
1.93 \text { ( } 95 \% \mathrm{Cl} 1.67-2.23 \text {. Adjusted OR for BD: } 1.95(1.68- \\
\text { 2.26) when the control group was the referent }(=1.00) \text {, } \\
\text { adjusted for: maternal age, income quintile, hypertension, } \\
\text { venous thromboembolic disease, gestational diabetes } \\
\text { mellitus, gestational hypertension, preeclampsia/ } \\
\text { eclampsia. Preterm birth defined as }<32 \text { gestational } \\
\text { weeks. BD did have increased risk. } N=34,9.1 \% \text {. Referent } \\
\text { group } n=4884,1.1 \% \text {. AOR: } 1.70 \text { ( } 95 \% \mathrm{Cl} 1.16-2.48) \text {. } \\
\text { Preterm birth defined as }<28 \text { gestational weeks. No } \\
\text { significant increased risk. }\end{array}$ & None & None \\
\hline
\end{tabular}

BD Bipolar Disorder, CI Confidence Interval, AOR Adjusted Odds Ratio, OR Odds Ratio

\section{Preterm birth (before 37 weeks gestation)}

Three studies examined this issue and found a combined prevalence of $10.68 \%$ for preterm birth (PTB) in women with BD (328 out of 3070), compared with a rate of $6.12 \%$ in women with no mental health problems $(79,030$ out of $1,291,682)$. This was a statistically significant difference $(\mathrm{Z}=10.37, p<0.0001$, OR 1.83, $95 \% \mathrm{CI}$ 1.64 to 2.06).

Bodén et al. [69] found that the risk of PTB was increased for women with BD compared with women without BD (4.80\%), both for those treated (8.10\%, AOR 1.50, $95 \%$ CI 1.01 to 2.24 ) and untreated (7.60\%, AOR 1.48, 95 \% CI 1.08 to 2.03), when adjusted for birth order, maternal age, cohabitation, smoking, height, alcoholism and substance misuse. Lee and Lin [70] similarly showed that women with $\mathrm{BD}$ were more likely to have PTB (14.20\% vs $6.90 \%$ ) than women with no history of mental health difficulties (AOR 2.08, 95 \% CI 1.53-2.83), when adjusted for maternal age, education level, marital status, infant gender, parity, family months income, parental age difference and parental education level. Mei-Dan et al. [71] also found a higher prevalence of PTB for women with BD (11.40\%), (AOR 1.95, $95 \%$ CI 1.68-2.26) compared with the control group (6.20\%), when adjusted for maternal age, parity, obesity, substance abuse and medical and obstetric complications.

Early preterm occurrence was studied in the Canadian study. Preterm birth defined as $<32$ gestational weeks was increased: $9.1 \%$ vs $1.1 \%$. AOR: 1.70 (95\% CI 1.162.48). Preterm birth defined as $<28$ gestational weeks show no significant increased risk: BD $0.9 \%$ vs $0.6 \%$ in the referent group (AOR 1.66; $95 \%$ CI 0.92-3.02) [71].

\section{Mode of birth}

Mode of birth was reported in one study, the Swedish cohort. Compared to women without BD emergency caesarean section was about $50 \%$ increased in women with BD. Adjustment was done for birth order, maternal age, cohabitation, smoking, height, alcoholism and substance misuse. For untreated women the AOR was 1.45 (95\% CI 1.18 to 1.78 ), and in treated women it was 1.56 (95\% CI 1.20-2.03). Similar results were found for vaginal instrumental birth (vacuum extraction or forceps): AOR in untreated BD was 1.49 (95\% CI 1.18-1.78), and treated BD women AOR 1.39 (95\% CI 1.20-2.03) [69].

\section{Fetal and neonatal outcomes (Table 6) \\ Congenital anomalies}

Congenital abnormalities (CA) were examined in three studies. Jablensky et al. [67] found no difference in congenital abnormalities in women with $\mathrm{BD}(n=62$ out of $1,301,4.80 \%)$ compared with those with no mental health difficulties ( $n=152$ out of $3,129,4.90 \%$ ), but is not included in the meta-analysis.

The combined results of the other two studies $[69,71]$ showed that 21,632 women without BD had a baby with congenital abnormality, out of 766,750 (2.82 \%), while 175 women with BD, out of 4034 , had one (4.34\%). This difference is statistically significant (chi-square $=33.59$, $p<0.0001$, OR 1.56, $95 \%$ CI 1.34 to 1.82 ). There was no heterogeneity shown between the two studies: $\mathrm{Chi}^{2}=$ 0.02 , df = $1(P=0.90) ; \mathrm{I}^{2}=0 \%$.

Mei-Dan et al. [71] found that BD presented increased risk for congenital anomalies $(n=90$ out of 1859, $5.00 \%)$ compared with the referent group ( $n=14,963$ out of 432,358, $3.50 \%$ ), when adjusted for maternal age and parity (AOR 1.48, $95 \%$ CI 1.20-1.82). Bodén et al. [69] also found the prevalence of congenital malformations was $2 \%$ for infants born to women without BD (i.e., the normal population). For women with BD who were not treated with mood stabilisers the rate was $1.90 \%$, and those women with BD who were treated with mood stabilisers had rates ranging from 0 to $3.50 \%$, depending on the drug used. The authors did not compare these results statistically; however, if the results for women without $\mathrm{BD}$ and the women with no 
Table 6 Fetal and neonatal complications in babies of women with bipolar disorder

\begin{tabular}{|c|c|c|c|}
\hline $\begin{array}{l}\text { First author, year of } \\
\text { publication }\end{array}$ & Key findings: reported by authors & $\begin{array}{l}\text { Potential mechanisms } \\
\text { suggested by authors }\end{array}$ & $\begin{array}{l}\text { Key recommendations made } \\
\text { by authors }\end{array}$ \\
\hline \multicolumn{4}{|l|}{ Low birthweight } \\
\hline Jablensky 2005 [67] & $\begin{array}{l}\text { Defined as < percentage estimated birth weight } \\
<10 \text { th percentile. Women with BD were NOT } \\
\text { more likely to have LBW infants ( } 9.9 \% \text { vs.9.3 \%) } \\
\text { than pregnant women with no history of mental } \\
\text { health difficulties. } \\
\text { This cohort included only } 55 \% \text { of women with } \\
\text { pre-existing BD, who had a significantly increased } \\
\text { risk of obstetric complications (OR } 1.13,95 \% \mathrm{Cl}= \\
1.02-1.25 \text { ), whereas those who developed BD } \\
\text { after the index birth were at no more risk than } \\
\text { the women without mental health difficulties } \\
\text { (OR } 1.02,95 \% \mathrm{Cl}=0.92-1.12 \text { ) (Chi-square }=157.56 \text {, } \\
\mathrm{df}=8, p<0.0001 \text { ). }\end{array}$ & None & None \\
\hline
\end{tabular}

Lee 2010 [70] Women with BD were more likely to have low birth weight infants (9.8\% vs.5.7 \%) than pregnant women with no history of mental health difficulties (AOR 1.66 (95\% Cl 1.16-2.38)).

\section{SGA}

Bodén 2012 [69]

Jablensky 2005 [67]

Lee 2010 [70]

Mei-Dan 2015 [71]

LGA

Mei-Dan 2015 [71]

\section{Congenital anomalies}

Bodén 2012 [69]

Jablensky 2005 [67]

Mei-Dan 2015 [71]
No significant results for SGA were reported for women with $\mathrm{BD}$ (neither for the group treated with mood stabilisers nor for those not treated).

No difference found in SGA in women with $\mathrm{BD}$ compared with those with no mental health difficulties.

Women with $\mathrm{BD}$ were more likely to have SGA ( $22.3 \%$ vs. $15.7 \%$ ) than pregnant women with no history of mental health difficulties (AOR 1.47 (95\% Cl 1.14-1.91)).

Severe SGA (<3rd percentile), was not significantly elevated in $\mathrm{BD}(n=84,4.6 \%$; AOR $1.15(95 \% \mathrm{Cl} 1.05-1.42)$ compared with the referent group $(n=16.823,3.9 \%)$. SGA ( $<10$ th percentile): BD presented increased risk compared to reference group: BD: $n=258$ of $185914.1 \%$, reference group $n=5485812.8 \%$. AOR 1.17 (95\%Cl 1.03-1.34). Adjusted for: maternal age, income quintile, hypertension, venous thromboembolic disease, gestational diabetes, gestational hypertension, pre-eclampsia/eclampsia

Severe LGA (>97th percentile) was significantly more common among women with $\mathrm{BD}(n=69,3.8 \%$; AOR 1.29. $95 \% \mathrm{Cl} 1.08-1.54$ ). Reference group $2.7 \%, n=11712$. Adjusted for: maternal age, income quintile, hypertension, venous thromboembolic disease, and gestational diabetes, gestational hypertension, pre-eclampsia/eclampsia LGA (>90th percentile) was NOT significantly more common. BD 167 of $18599.1 \%$ compared to referent without mental illness $n=35,158$ 8.2 \%. AOR 1.13 (0.96.1.32).

Congenital malformations in infants born to women: without BD: $2.0 \%$; with $\mathrm{BD}$ without treatment with mood stabilisers: $1.9 \%$; with BD with treatment with mood stabilisers: 0 to $3.5 \%$, depending on the drug used, average $3.4 \%$ (Numbers calculated by this review team).

No difference found in congenital abnormalities in women with $\mathrm{BD}$ compared with those with no mental health difficulties.

BD did present increased risk for congenital anomalies. $\mathrm{BD} n=90,0.5 \%$. Referent group $n=14963,3.5 \%$. AOR: 1.48 (95\% Cl 1.20-1.82) Adjusted for: maternal age, income quintile, hypertension, venous thromboembolic disease,
Smoking could be a large Monitoring of fetus, early part of the causation intervention if abnormalities are noted.

None

None

None

None

Smoking could be a large Monitoring of fetus, early part of the causation intervention if required.

None

Interventions should be evaluated, to optimise health of women with $\mathrm{BD}$
None

Interventions should be evaluated, to optimize health of women with $\mathrm{BD}$ 
Table 6 Fetal and neonatal complications in babies of women with bipolar disorder (Continued)

gestational diabetes, gestational hypertension, pre-eclampsia/eclampsia

Neonatal re-admissions

Mei-Dan 2015 [71]

Neonatal admission, $<28$ days of life. BD did have

None

None increased risk. $N=36,2.0 \%$ compared to referent $n=3953$, $0.9 \%$. AOR: 2.41 (95\% Cl 1.76-3.31) Adjusted for: maternal age, income quintile, hypertension, venous thromboembolic disease, and gestational diabetes, gestational hypertension, pre-eclampsia/eclampsia

Fetal distress

Jablensky 2005 [67]

No difference in fetal distress, cephalopelvic disproportion, atypical presentation, or cord anomalies, threatened preterm labor, early rupture of the membranes, prolonged labour, low 5-min Apgar scores, neonatal mortality in women with $\mathrm{BD}$ compared with those with no mental health difficulties.

Boden 2012 [69]

Showed no difference in low Apgar scores between women without BD and those untreated (AOR 1.56, $95 \%$ $\mathrm{Cl}=0.85-2.86$ ) and treated (AOR 0.88, $95 \% \mathrm{Cl}=0.33-2.34$ ) for $\mathrm{BD}$.

Stillbirth

Jablensky 2005 [67]

No difference found in stillbirths in women with BD compared with those with no mental health difficulties.

Mei-Dan 2015 [71]

did not present increased risk for stillbirth. $\mathrm{BD} n=11$ $0.6 \%$. Referent group $n=2235,0.5 \%$. AOR $1.20(955 \mathrm{Cl}$ 0.66-2.18), adjusted for: maternal age, income quintile, hypertension, gestational diabetes, gestational hypertension, venous thromboembolic disease, preeclampsia

Infant mortality

Mei-Dan 2015 [71]

Infant mortality $<28$ days of life. BD did not have increased or reduced risk $N=\leq 5$, referent group $n=1004,0.2 \%$. AOR 0.72 (0.23-2.23). Mortality $<1$ year of life. No difference in risk $\mathrm{BD} n=7,0.4 \%$ referent group $n=1389,0.3 \%$. AOR: 0.99 (95\% Cl 0.44-2.22)

Neonatal morbidity

Mei-Dan 2015 [71]

Secondary outcome; neonatal morbidity defined as RDS (respiratory distress syndrome), Seizure, sepsis, IVH (Intravenous hyperalimentation), persistent fetal circulation, and neonatal abstinence syndrome.

1. Any of these neonatal morbidities: BD had increased risk: $n=96,5.4 \%$. Referent group (without mental illness) $n=8270,1.9 \%$. AOR $2.99(95 \% \mathrm{Cl} 2.44-3.66)$

2. RDS: BD had increased risk. $N=26,1.5 \%$. Referent group: $n=4049,1.0 \%$. AOR 1.64 (95 \% Cl 1.13-2.39)

3. Seizure: $\mathrm{BD}$ had increased risk. $\mathrm{BD} n=10.0 .6 \%$, referent group $n=844,0.2 \%$. AOR $=2.54(95 \% \mathrm{Cl} 1.31-4.90)$.

4. Sepsis: $\mathrm{BD}$ had increased risk. $\mathrm{BD} n=23,1.3 \%$, referent group 3178, $0.7 \%$. AOR: 1.80 (95\% Cl 1.20-2.70)

5. IVH: $\mathrm{BD}$ had increased risk. $\mathrm{BD} n=13,0.7 \%$. Referent group $n=1485,0.3 \%$. AOR: 2.12 (95\% Cl 1.22-3.67).

6. Persistent fetal circulation. BD did NOT have increased risk. $\mathrm{BD} n=\leq 5$, referent group $n=615,0.1 \%$. AOR: 1.89 (95\% Cl 0.78-4.58).

7. Neonatal abstinent syndrome. BD had severe increased risk. $\mathrm{BD} n=70,1.9 \%$. Referent group $n=177,0.0 \%$. AOR $=52.2$ (95\% Cl 36.5-74.7)

Adjusted for: maternal age, income quintile, hypertension, venous thromboembolic disease, gestational diabetes, gestational hypertension, pre-eclampsia/eclampsia

None

None

None

None

None

None

None

None

None

None

None

None 
treatment for BD are combined (6528 abnormalities out of $331,817,2.00 \%$ ) and compared with the 12 abnormalities out of 320 women with BD who were treated (3.75\%), the difference is statistically significant $(\mathrm{Z}=$ 2.19, $p<0.03$, OR 1.91, $95 \%$ CI 1.07-3.39), indicating that medications for the treatment of $\mathrm{BD}$ in pregnancy are associated with fetal abnormalities.

\section{Small for gestational age (SGA)}

Findings were mixed in the four studies examining this outcome, and definitions differed. Boden et al. [69] used $\leq 2$ nd-3rd centile (severe SGA) and Mei-Dan et al. [71] used <3rd centile (severe SGA), while Jablensky et al. [67], Lee and Lin [70] and Mei-Dan et al's [71] secondary outcomes used $<10$ th centile. No significant results for severe SGA were reported for women with BD in Mei-Dan et al. [71] (4.6\% versus $3.9 \%$ ), or in Bodén et al's study [69] (3.33\% versus $2.30 \%)$, neither for the group treated with mood stabilisers nor for those not treated. However, combining results from the two studies gives prevalence rates of $4.14 \%$ for women with BD (113 out of 2729), compared with $3.20 \%$ for those without $(24,418$ out of 762,619$)$, a statistically significant difference $(Z=2.79, p<0.006$, OR 1.31, $95 \%$ CI 1.08 to 1.58$)$.

Results from the three studies that used the $<10$ th centile definition differed. Jablensky et al. [67] found no difference in women with BD compared with those with no mental health difficulties, but was not included in the meta-analysis.

Women with BD in Lee and Lin's research [70] were more likely to have SGA (22.3\% vs.15.7\%) than those with no history of mental health difficulties (OR 1.47, $95 \%$ CI 1.14-1.91). Mei-Dan et al. [71], in testing their secondary outcome of SGA using the $<10$ th centile definition, found that women with BD had an increased risk of SGA compared to the reference group, $13.9 \%$ compared to $12.7 \%$, AOR 1.17, $95 \%$ CI 1.03-1.34, when adjusted for maternal age and parity. When results from these last two studies are combined (15.2\% versus $14.3 \%)$, there is no significant difference using unadjusted odds ratio $(\mathrm{Z}=1.19, p=0.24$, OR $1.07,95 \%$ CI 0.96 to 1.21$)$. It would thus appear that women with $\mathrm{BD}$ are more likely to have babies with severe SGA ( $<2$ nd-3rd centile) but not SGA $(<10$ th centile).

\section{Large for gestational age fetus (LGA)}

In Mei-Dan et al.'s [71] study, severe LGA, defined as $>97$ th centile, was significantly more common among women with $\mathrm{BD}$ (3.8 \%), AOR 1.29, 95 \% CI 1.08-1.54, compared to women with no mental difficulties (2.7 \%), when adjusted for maternal age and parity. However, when LGA was defined as >90th centile, no difference was seen between the rates for women with BD $(9.10 \%)$ compared to women without mental illness (8.2\%), AOR 1.1395 \% CI 0.96-1.32.

\section{Low birthweight}

Two studies measured low birthweight (LBW), defined as the birth weight $<10$ th centile [67] or $<2,500 \mathrm{~g}$ [70]. In Jablensky et al's [67] study women with BD were not more likely to have LBW infants (9.9\% vs.9.3\%, OR $1.0695 \%$ CI 0.82-1.36) than pregnant women with no history of mental health difficulties. Women with BD in Lee and Lin's study [70] were more likely to have LBW infants $(9.8 \%$ vs.5.7 \%) than pregnant women with no history of mental health difficulties (OR 1.66, 95 \% CI $1.16-2.38)$.

\section{Fetal distress/low Apgar score}

Jablensky et al. [67] found no difference in fetal distress or low 5-min Apgar scores in women with BD compared to those with no mental health difficulties. Boden et al. [69] also showed no difference in low Apgar scores between women without $\mathrm{BD}$ and those untreated (AOR 1.56, $95 \% \mathrm{CI}=0.85-2.86$ ) and treated (AOR 0.88, $95 \%$ $\mathrm{CI}=0.33-2.34$ ) for $\mathrm{BD}$ in pregnancy.

\section{Stillbirth}

Neither Jablensky et al. [67] nor Mei-Dan et al. [71] found any difference in the rate of stillbirths in women with BD compared with those with no mental health difficulties.

\section{Neonatal readmissions}

Mei-Dan et al. [71] studied neonatal admission up to 28 days of life. Babies of women with BD did have an increased risk (2.0\%) compared to those of women with no mental health difficulties (0.9 \%) AOR 2.41, $95 \%$ CI 1.76-3.31, when adjusted for maternal age and parity.

\section{Infant mortality}

Infant mortality defined as death before the 28th day of life was studied by Mei-Dan et al. [71]. The risk for women with $\mathrm{BD}$ was the same as that for women with no mental health problems $(0.2 \%)$ AOR 0.72, $95 \% \mathrm{CI}$ $0.23-2.23$.

\section{Neonatal morbidity}

Neonatal morbidity, studied by Mei-Dan et al. [71] only, was defined as RDS (respiratory distress syndrome), seizure, sepsis, IVH (intravenous hyperalimentation), persistent fetal circulation, and neonatal abstinence syndrome. The risk of having any of these neonatal morbidities was higher in women with $\mathrm{BD}(5.4 \%)$ compared with those without mental illness (1.9 \%) AOR 2.99, 95 \% CI 2.443.66. When analysed separately, babies of women with 
BD had higher rates for RDS, seizure, sepsis, IVH and neonatal abstinence syndrome. No difference was seen between the two groups of women in persistent fetal circulation (AOR 1.89, 95 \% CI 0.78-4.58).

\section{Discussion}

This systematic review has presented the wide-ranging health outcomes for women with bipolar disorder and their fetuses/babies. Mental health risks to women include the occurrence of mood episodes during pregnancy, rates of which varied across the studies from 9 to $18 \%$. Mood episodes were more common in the postpartum period [73, 75], ranging from 25 to $79 \%$, with differences possibly due to small sample sizes in some studies [36, 44]. It has been suggested that this may be due to placental hormones increasing throughout pregnancy, and their abrupt cessation after birth [75]. In addition, mood episodes were found to be more common in first pregnancies [73]. Similar results were found in a recent meta-analysis [54]; this review differs in methodology from ours as it included women who had a psychotic or manic episode following childbirth, even if they had never had a diagnosis of BD in pregnancy. It also included papers that compared different medication regimes, or stopping treatment at different times, which we chose to exclude as there are so many different treatments. Perhaps because of this, our postpartum relapse rate (79\%) was much higher than that quoted by Wesseloo et al. [54].

Single studies showed some incidence of increased risks in pregnancy; induction of labour occurred in women with $\mathrm{BD}$, both treated and untreated, with rates of 31 and $38 \%$ respectively, compared with $21 \%$ in women without BD. Caesarean section rates were similarly increased. Women with BD were also more likely to have gestational hypertension [70], antepartum haemorrhage and placenta praevia [67]. Emergency caesarean section was about $50 \%$ increased in women with $\mathrm{BD}$, and similar results were found for vaginal instrumental birth [69]. There was no increased risk of gestational diabetes found $[69,70]$. Pre-term birth showed a difference $(10.68 \%$ versus $6.12 \%$, two studies, total population 1,294,752). Lee and Lin [70] believed that smoking could be a large part of the causation, as in their (and other) studies women with BD had a higher prevalence of smoking behaviour.

Babies of women with BD have a higher prevalence of congenital abnormalities (4.34 \% versus $2.82 \%$, two studies, total population 770,784$)$, although the three papers examined differed in their individual findings. The difference is likely due to the smaller sample size in Jablensky's work [67], at just over 6,000, and to the fact that this cohort included only $55 \%$ of women with preexisting BD. Other factors include the separation of women treated and un-treated for BD in Boden's study [69], and the fact that Mei-Dan's study population [71] were women previously hospitalised for bipolar disorder, so it is likely that they were on medication for their BD symptoms. There are many studies showing that mood stabilisers do cause congenital abnormalities, and that was not the focus of this review. It would appear from the three papers summarised here that women with $\mathrm{BD}$ who are not being treated with mood stabilisers in pregnancy might not be at the same level of increased risk of congenital abnormalities. Lee and Lin [70] recommended active monitoring of the fetus in pregnancy, and early intervention if abnormalities are noted.

A new result demonstrated by the meta-analysis in this review was that severe SGA ( $<2$ nd-3rd centile) was increased in women with BD (4.14 \% versus $3.20 \%$, two studies, total population 765,348 ), in addition to previously reported increases in SGA based on the $<10$ th centile definition [70, 71]. Again, smoking behaviour may be the main cause, as suggested by both Lee and Lin [70] and Jablensky et al. [67].

Large for gestational age babies, low birthweight, fetal distress, low Apgar score, still-birth, neonatal readmissions, infant mortality and neonatal morbidity were all examined by individual studies only, or in two studies that could not be merged for meta-analysis. Large for gestational age babies defined as $>97$ th centile, but not as $>90$ th centile, were more common in women with BD [71], as were low birthweight babies [70], neonatal readmissions [71] and any neonatal morbidity [71]. Fetal distress [67], low Apgar score [67, 69], still-birth [67, 71], and infant mortality [71] showed no difference.

One paper published after the systematic review was finished [51] showed that women with BD had lower scores on maternal-infant interaction at 12 months postpartum; this is an area that would benefit from further study. Marengo et al. [52], also published after the systematic review was finished, highlighted results related to reproduction decisions of women with $\mathrm{BD}$. They showed that women with BD had more unplanned pregnancies (37.7 \% versus $9.6 \%$ ) and fewer planned pregnancies $(32.8 \%$ versus $78.1 \%)$ than women in the control group. They also found that women with BD more often than those without had electively interrupted at least one pregnancy (42.4\% versus $13.5 \%$ ). These findings indicate that the complex picture of problems for women with $\mathrm{BD}$, mentioned in the introduction, need to be further explored.

\section{Review strengths and limitations}

This is the first review, to our knowledge, that systematically searched the literature and summarised the risks associated with bipolar disorder for pregnant women and their babies. A key strength is the sourcing of 
literature from all languages. The result is a concise, extensive review that includes outcomes for both mother and baby, and spans both physical and mental health. Given the heterogeneity of data, particularly the use of differing definitions of bipolar disorder, and of some outcomes, we were unable to perform a meta-analysis for all outcomes.

\section{Conclusions}

A clear negative impact of bipolar disorder on mothers' and their babies' health has been shown. Adverse outcomes such as gestational hypertension and antepartum haemorrhage occur in pregnant women with bipolar disorder. They are also prone to increased rates of induction of labour and caesarean section, and have an increased risk of mood disorders in the postnatal period. The risk of fetuses developing severe growth retardation ( $<2$ nd-3rd centile) is increased in women with BD, and increased neonatal morbidity is also found. In addition, bipolar disorder is linked to a higher incidence of congenital abnormalities (if woman are treated with mood stabilisers) and neonatal readmissions. These negative outcomes lead to longer duration of hospital stay and increase the costs of care. Active monitoring of the fetus in pregnancy, early intervention if abnormalities are noted, encouragement to decrease smoking behaviour and close support and monitoring of the mother's mood postpartum are all likely to bring benefits in terms of improved future health and decreased monetary outlay.

As only nine papers were suitable for inclusion in this review, and as some of the studies did not control for confounding variables, or included differing populations, further research is required. In particular, large cohort studies examining fetal abnormality outcomes for women with $\mathrm{BD}$ who are not on mood stabilisers in pregnancy are required, as are studies on maternalinfant interaction. More qualitative studies are also recommended regarding these women's perspectives of pregnancy, childbirth and early motherhood. The compilation of these outcomes should be used to guide more informed and supportive care for women with bipolar disorder who embark on pregnancy and motherhood.

\section{Additional file}

Additional file 1: Bipolar disorder in pregnancy and childbirth: a systematic review of outcomes. (DOC $214 \mathrm{~kb}$ )

\section{Abbreviation}

BD: Bipolar disorder

\section{Acknowledgements}

The authors would like to thank all the authors and publishers of the original studies.

\section{Funding}

This study was not funded by any external sources.

\section{Availability of data and material}

Data sharing is not applicable to this article as no datasets were generated or analysed during the current study. The papers that were included in the literature searches have been organised in an EndNote Library held by the first author.

\section{Authors' contributions}

All authors (MR, MB and $C B$ ) have made substantial contributions to conception and design, revision of the literature searches, assessement of the studies for quality, data extraction, analysis and interpretation of the data as well as drafting and revising the manuscript. All authors have approved the final manuscript. MR undertook the literature searches and coordinated the systematic review process.

\section{Competing interests}

The authors declare that they have no competing interests.

Consent for publication

Not applicable.

Ethics approval and consent to participate

Ethics approval was not needed for this systematic literature review.

\section{Author details}

${ }^{1}$ Department of Research, Södra Älvsborgs Hospital, Brämhultsvägen 53, SE-501 82 Borås, Sweden. ${ }^{2}$ Institute of Health and Care Sciences, Sahlgrenska Academy, University of Gothenburg, Gothenburg, Sweden. ${ }^{3}$ Centre for Person-Centred Care (GPCC), University of Gothenburg, Gothenburg, Sweden. ${ }^{4}$ School of Nursing and Midwifery, Trinity College Dublin, Dublin 2, Ireland.

Received: 16 July 2016 Accepted: 22 October 2016

Published online: 28 October 2016

\section{References}

1. APA. Diagnostic and Statistical Manual of Mental Disorders, 5th Edition. In. https://www.psychiatry.org/psychiatrists/practice/dsm. Accessed 12 Jul 2016: American Psychiatric Association; 2013

2. WHO. International Statistical Classification of Diseases, 10th Revision. In. http://www.who.int/classifications/icd/en/. Accessed 12 Jul 2016: World Health Organization; 2011

3. Merikangas KR, Akiskal HS, Angst J, et al. Llfetime and 12-month prevalence of bipolar spectrum disorder in the national comorbidity survey replication. Arch Gen Psychiatry. 2007;64(5):543-52.

4. Merikangas KR, Jin R, He J, et al. PRevalence and correlates of bipolar spectrum disorder in the world mental health survey initiative. Arch Gen Psychiatry. 2011;68(3):241-51.

5. Carlborg A, Ferntoft L, Thuresson M, Bodegard J. Population study of disease burden, management, and treatment of bipolar disorder in Sweden: a retrospective observational registry study. Bipolar Disord. 2015;17(1):76-85.

6. Ekman $\mathrm{M}$, Granström $\mathrm{O}$, Omérov $\mathrm{S}$, Jacob J, Landén $\mathrm{M}$. The societal cost of bipolar disorder in Sweden. Soc Psychiatry Psychiatr Epidemiol. 2013;48(10): 1601-10.

7. Pompili M, Gonda X, Serafini G, Innamorati M, Sher L, Amore M, Rihmer Z, Girardi P. Epidemiology of suicide in bipolar disorders: a systematic review of the literature. Bipolar Disord. 2013;15(5):457-90.

8. Kessler RC, Berglund P, Demler O, Jin R, Merikangas KR, Walters EE. Llfetime prevalence and age-of-onset distributions of dsm-iv disorders in the national comorbidity survey replication. Arch Gen Psychiatry. 2005;62(6): 593-602.

9. Nelson AM. Transition to motherhood. J Obstet Gynecol Neonatal Nurs. 2003;32(4):465.

10. Patel V, Kirkwood BR, Pednekar S, et al. Gender disadvantage and reproductive health risk factors for common mental disorders in women: A community survey in india. Arch Gen Psychiatry. 2006;63(4):404-13.

11. Özcan NK, Boyacıoğlu NE, Enginkaya S, Dinç H, Bilgin H. Reproductive health in women with serious mental illnesses. J Clin Nurs. 2014;23(9-10):1283-91.

12. McCandless F, Sladen C. Sexual health and women with bipolar disorder. J Adv Nurs. 2003;44(1):42-8. 
13. Miller LJ, Ghadiali NY, Larusso EM, Wahlen KJ, Avni-Barron O, Mittal L, Greene JA. Bipolar Disorder in Women. Health care for women international. 2015;36(4):475-98.

14. Viguera AC, Whitfield T, Baldessarini RJ, Newport DJ, Stowe Z, Reminick A, Zurick A, Cohen LS. Risk of recurrence in women with bipolar disorder during pregnancy: prospective study of mood stabilizer discontinuation. Am J Psychiatr. 2007;164(12):1817

15. Grof P, Robbins W, Alda M, Berghoefer A, Vojtechovsky M, Nilsson A Robertson C. Protective effect of pregnancy in women with lithiumresponsive bipolar disorder. J Affect Disord. 2000;61(1-2):31-9.

16. Hariri AG, Karadag F, Gokalp P, Essizoglu A. Risky Sexual Behavior among Patients in Turkey with Bipolar Disorder, Schizophrenia, and Heroin Addiction. J Sex Med. 2011:8(8):2284-91.

17. Sampson M, McGowan J, Cogo E, Grimshaw J, Moher D, Lefebvre C. An evidence-based practice guideline for the peer review of electronic search strategies. J Clin Epidemiol. 2009;62(9):944-52.

18. Aoki FY, Ruedy J. Severe lithium intoxication: management without dialysis and report of a possible teratogenic effect of lithium. Can Med Assoc J. 1971;105(8):847-8.

19. Austin M-PV, Mitchell PB. Use of psychotropic medications in breast-feeding women: Acute and prophylactic treatment. Aust N Z J Psychiatry. 1998; 32(6):778-84.

20. Barbui C, Conti V, Purgato M, Cipriani A, Fortino I, Rivolta AL, Lora A. Use of antipsychotic drugs and mood stabilizers in women of childbearing age with schizophrenia and bipolar disorder: Epidemiological survey. Epidemiol psychiatr sci. 2013;22(4):355-61.

21. Bergink V, Bouvy PF, Vervoort JSP, Koorengevel KM, Steegers EAP, Kushner SA. Prevention of postpartum psychosis and mania in women at high risk. Am J Psychiatry. 2012;169(6):609-15

22. Clark CT, Klein AM, Perel JM, Helsel J, Wisner KL. Lamotrigine dosing for pregnant patients with bipolar disorder. Am J Psychiatr. 2013;170(11): 1240-7

23. Diav-Citrin O, Einarson A. Lithium exposure during pregnancy linked with cardiovascular defects. Brown University Psychopharmacol Update. 2014; 25(8):1-6.

24. Gentile S. Prophylactic treatment of bipolar disorder in pregnancy and breastfeeding: Focus on emerging mood stabilizers. Bipolar Disord. 2006; 8(3):207-20.

25. Goldstein DJ, Corbin LA, Fung MC. Olanzapine-exposed pregnancies and lactation: Early experience. J Clin Psychopharmacol. 2000;20(4):399-403.

26. Iqbal MM, Sohhan T, Mahmud SZ. The effects of lithium, valproic acid, and carbamazepine during pregnancy and lactation. J Toxicol Clin Toxicol. 2001; 39(4):381-92.

27. Bergink V, Burgerhout KM, Koorengevel K, Kamperman AM, Hoogendijk WJ, den Berg MP L-V, Kushner SA. Treatment of psychosis and mania in the postpartum period. Am J Psychiatry. 2015;172(2):115-23.

28. Diav-Citrin O, Shechtman S, Tahover E, Finkel-Pekarsky V, Arnon J, Kennedy D, Erebara A, Einarson A, Ornoy A. Pregnancy outcome following in utero exposure to lithium: a prospective, comparative, observational study. Am J Psychiatr. 2014;171(7):785-94.

29. Even C, Dorocant ES, Thuile J, Kalck-Stern M, Guelfi JD. Pregnancy, breast feeding and mood stabilisers: Review and recommendations for practice. L'Encéphale. 2006;32(2):224-30.

30. Galbally M, Roberts M, Buist A. Mood stabilizers in pregnancy: a systematic review. Aust NZ J Psychiatry. 2010;44(11):967-77.

31. Newport DJ, Viguera AC, Beach AJ, Ritchie JC, Cohen LS, Stowe ZN. Lithium placental passage and obstetrical outcome: implications for clinical management during late pregnancy. Am J Psychiatr. 2005;162(11):2162-70.

32. Troyer WA, Pereira GR, Lannon RA, Belik J, Yoder MC. Association of maternal lithium exposure and premature delivery. J Perinatol. 1993;13(2):123-7.

33. Yacobi S, Ornoy A. Is lithium a real teratogen? What can we conclude from the prospective versus retrospective studies? A review. Isr J Psychiatry Relat Sci. 2008;45(2):95-106

34. Zalzstein E, Koren G, Einarson T, Freedom RM. A case-control study on the association between first trimester exposure to lithium and Ebstein's anomaly. Am J Cardiol. 1990;65(11):817-8.

35. Kallen B, Tandberg A. Postpartum mania. Acta Psychiatr Scand. 1983;68(2):134-9.

36. Cohen LS, Sichel DA, Robertson LM, Heckscher E, Rosenbaum JF. Postpartum prophylaxis for women with bipolar disorder. Am J Psychiatry. 1995;152(11):1641-5.

37. Viguera AC, Nonacs R, Cohen LS, Tondo L, Murray A, Baldessarini RJ. Risk of recurrence of bipolar disorder in pregnant and nonpregnant women after discontinuing lithium maintenance. Am J Psychiatr. 2000; 157(2):179-84.

38. Sharma V, Xie B, Campbell MK, Penava D, Hampson E, Mazmanian D, Pope CJ. A prospective study of diagnostic conversion of major depressive disorder to bipolar disorder in pregnancy and postpartum. Bipolar Disord. 2014;16(1):16-21.

39. van der Lugt NM, van de Maat JS, van Kamp IL, der Klein EAM K-V, Hovens JGFM, Walther FJ. Fetal, neonatal and developmental outcomes of lithiumexposed pregnancies. Early Hum Dev. 2012;88(6):375-8.

40. Heron J, Haque S, Oyebode F, Craddock N, Jones I. A longitudinal study of hypomania and depression symptoms in pregnancy and the postpartum period. Bipolar Disord. 2009;11(4):410-7.

41. Kinney DK, Yurgelun-Todd DA, Levy DL, Medoff D, Lajonchere CM, RadfordParegol M. Obstetrical complications in patients with bipolar disorder and their siblings. Psychiatry Res. 1993;48(1):47-56.

42. Webb RT, Pickles AR, King-Hele SA, Appleby L, Mortensen PB, Abel KM. Parental mental illness and fatal birth defects in a national birth cohort. Psychol Med. 2008;38(10):1495-503.

43. Howard LM, Goss C, Leese M, Appleby L, Thornicroft G. The psychosocial outcome of pregnancy in women with psychotic disorders. Schizophr Res. 2004;71(1):49-60.

44. Browne R, Byrne M, Mulryan N, Scully A, Morris M, Kinsella A, McNeil TF, Walsh D, O'Callaghan E. Labour and delivery complications at birth and later mania: An Irish case register study. Br J Psychiatry. 2000;176: 369-72.

45. Kadrmas A, Winokur G, Crowe RR. Postpartum mania. Br J Psychiatry. 1979; 135:551-4.

46. Doyle K, Heron J, Berrisford G, Whitmore J, Jones L, Wainscott G, Oyebode $F$. The management of bipolar disorder in the perinatal period and risk factors for postpartum relapse. Eur Psychiatry. 2012;27(8):563-9.

47. MacCabe JH, Martinsson L, Lichtenstein P, Nilsson E, Cnattingius S, Murray RM, Hultman CM. Adverse pregnancy outcomes in mothers with affective psychosis. Bipolar Disord. 2007;9(3):305-9.

48. Gowan J, Roller L. Bipolar disorder: Pregnancy and breastfeeding. Aust J of Pharm. 2004;85(1008):203-7.

49. Weinstein MR, Goldfield MD. Cardiovascular malformations with lithium use during pregnancy. Am J Psychiatr. 1975;132(5):529-31.

50. El-Badri SM, Ashton HC, Ferrier IN, Moore PB. Family illness history, obstetric complications and age of onset in bipolar patients. Open Neuropsychopharmacol J. 2009;2:11-5.

51. Logsdon MC, Mittelberg M, Jacob AE, Luther JF, Wisniewski SR, Confer A, Eng $\mathrm{H}$, Wisner KL. Maternal-Infant interaction in women with unipoloar and bipolar depression. Appl Nurs Res. 2015;28(4):381-3.

52. Marengo E, Martino DJ, Igoa A, Scapola M, Fassi G, Baamonde MU, Strejilevich SA. Unplanned pregnancies and reproductive health among women with bipolar disorder. J Affect Disord. 2015;178:201-5.

53. Taylor CL, Stewart R, Ogden J, Broadbent M, Pasupathy D, Howard LM. The characteristics and health needs of pregnant women with schizophrenia compared with bipolar disorder and affective psychoses. BMC psychiatry. 2015;15:88.

54. Wesseloo R, Kamperman AM, Munk-Olsen T, Pop VJ, Kushner SA, Bergink V. Risk of Postpartum Relapse in Bipolar Disorder and Postpartum Psychosis: A Systematic Review and Meta-Analysis. Am J Psychiatry. 2016:173(2):117-27.

55. EPHPP. Effective Public Health Practice Project. In. http://ephpp.ca/. Accessed 12 Jul 2016: The Effective Public Health Practice Project; 1999.

56. Blackmore ER, Jones I, Doshi M, Haque S, Holder R, Brockington I, Craddock N. Obstetric variables associated with bipolar affective puerperal psychosis. Br J Psychiatry. 2006;188(1):32-6.

57. Bratfos $\mathrm{O}$, Haug J. Puerperal mental disorders in manic-depressive females. Acta Psychiatr Scand. 1996;42(3):285-94.

58. Di Florio A, Jones L, Forty L, Gordon-Smith K, Craddock N, Jones I. Bipolar disorder, miscarriage, and termination. Bipolar Disord. 2014:17(1):102-5.

59. Hunt N, Silverstone T. Does puerperal illness distinguish a subgroup of bipolar patients? J Affect Disord. 1995;34(2):101-7.

60. Reich T, Winokur G. Postpartum psychoses in patients with manic depressive disease. J Nerv Ment Dis. 1970;151(1):60-8.

61. Robertson E, Jones I, Haque S, Holder R, Craddock N. Risk of puerperal and non-puerperal recurrence of illness following bipolar affective puerperal (post-partum) psychosis. Br J Psychiatry. 2005;186(3):258-9.

62. Shea BJ, Grimshaw JM, Wells GA, Boers M, Andersson N, Hamel C, Porter AC, Tugwell P, Moher D, Bouter LM. Development of AMSTAR: a measurement 
tool to assess the methodological quality of systematic reviews. BMC Med Res Methodol. 2007;7(1):10.

63. Sharif MO, Janjua-Sharif FN, Sharif FNJ, Ali H, Ahmed F. Systematic reviews explained: AMSTAR-how to tell the good from the bad and the ugly. Oral health dental manag. 2013;12(1):9.

64. Chaudron LH, Pies RW. The relationship between postpartum psychosis and bipolar disorder: A review. J Clin Psychiatry. 2003;64(11):1284-92.

65. Sharma V, Pope CJ. Pregnancy and bipolar disorders: A systematic review. J Clin Psychiatry. 2012;73(11):1447-55.

66. Özerdem A, Akdeniz F. Pregnancy and postpartum in bipolar disorder. Neuropsychiatry. 2014;4(1):95-107.

67. Jablensky AV, Morgan V, Zubrick SR, Bower C, Yellachich LA. Pregnancy, delivery, and neonatal complications in a population cohort of women with schizophrenia and major affective disorders. Am J Psychiatr. 2005; 162(1):79-91.

68. Akdeniz F, Vahip S, Pirildar S, Vahip I, Doganer I, Bulut I. Risk Factors Associated with Childbearing-Related Episodes in Women with Bipolar Disorder. Psychopathology. 2003;36(5):234-8

69. Bodén R, Lundgren M, Brandt L, Reutfors J, Andersen M, Kieler H. Risks of adverse pregnancy and birth outcomes in women treated or not treated with mood stabilisers for bipolar disorder: Population based cohort study. BMJ. 2012;345:e7085.

70. Lee H-C, Lin H-C. Maternal bipolar disorder increased low birthweight and preterm births: A nationwide population-based study. J Affect Disord. 2010; 121(1-2):100-5.

71. Mei-Dan E, Ray JG, Vigod SN. Perinatal outcomes among women with bipolar disorder: a population-based cohort study. Am J Obstet Gynecol. 2015;212(3):367. e361-368.

72. Munk-Olsen T, Laursen T, Mendelson T, Pedersen CB, Mors O, Mortensen P. Rlsks and predictors of readmission for a mental disorder during the postpartum period. Arch Gen Psychiatry. 2009;66(2):189-95.

73. Di Florio A, Forty L, Gordon-Smith K, Heron J, Jones L, Craddock N, Jones I. Perinatal episodes across the mood disorder spectrum. JAMA psychiatry. 2013;70(2):168-75.

74. Di Florio A, Jones L, Forty L, Gordon-Smith K, Blackmore ER, Heron J, Craddock N, Jones I. Mood disorders and parity —A clue to the aetiology of the postpartum trigger. J Affect Disord. 2014;152-154:334-9.

75. Grof P, Robbins W, Alda M. Protective effect of pregnancy in women with lithium-responsive bipolar disorder. Primary Care Companion J Clin Psychiatry. 2001;3(2):87

76. Spitzer RL, Endicott J, Robins E. Research diagnostic criteria: Rationale and reliability. Arch Gen Psychiatry. 1978;35(6):773-82.

\section{Submit your next manuscript to BioMed Central and we will help you at every step:}

- We accept pre-submission inquiries

- Our selector tool helps you to find the most relevant journal

- We provide round the clock customer support

- Convenient online submission

- Thorough peer review

- Inclusion in PubMed and all major indexing services

- Maximum visibility for your research

Submit your manuscript at www.biomedcentral.com/submit

C) Biomed Central 